\title{
Clinical and Investigational Profile of Adult Patients Suggestive of Dengue Fever at Teritiary Care Mamata General Hospital
}

\author{
Authors \\ Dilip M Rampure ${ }^{1}$, Rajhounsh $\mathbf{V}^{2}$,Subash Dasarapu ${ }^{3}$ \\ ${ }^{1}$ Professor and HOD, Department of General Medicine, Mamata Medical College \& General Hospital, \\ Khammam 507002, Telangana \\ ${ }^{2}$ Assitant Professor, Department of General Medicine, Mamata Medical College \& General Hospital, \\ Khammam 507002, Telangana \\ ${ }^{3}$ Post Graduate, Department of General Medicine, Mamata Medical College \& General Hospital, \\ Khammam 507002, Telangana \\ Corresponding author \\ Dr Subash.Dasarapu \\ Department of General Medicine, Mamata General Hospital, Khammam, Telangana 507002, india \\ Mail ID: subashdasarapu@gmail.com, Contact No: 9533495263
}

\begin{abstract}
Introduction: Dengue fever epidemic $s$ have been causing major concern in India, many parts of India are endemic for the dengue. Dengue is mosquito borne infection caused by 4 distinct serotypes deny-1, v-2, v-3, v4.v-3 is most prevalent serotype in last few years. Dengue illness often confused with other febrile states, this difficulty is especially striking during early phase of illness, when non specific clinical symptoms accompany the febrile illness.

Objective: Objective of the study is to document various clinical manifestations and laboratory parameters of all dengue cases.

Materials And Methods: Study conducted at Mamata general hospital during june2014-july 2015.This is a prospective study conducted on 100 cases who were presented with fever and admitted in hospital. A detailed history and clinical examination findings were recorded and all cases were subjected to laboratory investigations. Which included complete heamogram, mean plc, mean hematocrit, mean hb. all the patients were treated symptomatically.

Results: Among 100 serologically confirmed dengue cases the male and female ratio was l:l. the most common age group affected was 21-30years and most common presenting complaint was fever seen in 98\%.mean duration of fever was 6.1 day. Among the cases 56\% developed thrombocytopenia. In them 2 patients were having plc of 20000. Among 56\% 3 cases developed DHF and DSS, 4 cases developed bleeding manifestations. 39\% developed leucopenia.

Conclusion: This study showed that most common presentation was fever and 56\%patients presented with thrombocytopenia but rarely developed bleeding manifestations and complications. cases developed bleeding manifestations. 39\% developed leucopenia.

Keywords: Dengue fever, thrombocytopenia, hemogram
\end{abstract}




\section{INTRODUCTION}

Dengue is an endemic viral disease affecting tropical and subtropical regions around the world, predominantly in urban and semi urban areas. Dengue fever (DF) and its more serious forms, dengue hemorrhagic fever (DHF) and dengue shock syndrome (DSS), are becoming important public health problems. The disease is now endemic in more than 100 countries. In Africa, the Americas, the Eastern Mediterranean, Southeast Asia, and the Western pacific, threatening more than 2.5 billion people. Dengue virus is a mosquito-borne flavivirus and the most prevalent arbovirus in tropical and subtropical regions of the world. Dengue virus is a positive-stranded encapsulated RNA virus. There are four distinct serotypes, serotypes I to 4 . infection induces a life-long protective immunity to the homologous serotype but confers only partial and transient protection against subsequent infections by the other three serotypes. Instead, it has generally been accepted that secondary infection or infection with secondary or multiple infections with various dengue virus serotypes is a major risk factor for DHF, DSS due to antibody dependent enhancement 8,9,10,11. Other factors have been postulated to be important in the pathogenesis of DHF, including viral virulence 12, 13. host genetic background4. t-cell activatio14,15'.the viral burden16', and autoantibodies17,18. As attempts to eradicate aedes aegypti. the most efficient mosquito vector of dengue virus arc not successful in countries where Dengue is endemic. Dengue virus causes a broad spectrum of illnesses, ranging from in apparent infection, flu-like mild undificrentiated fever. and classical DF to the more severe form DHF-DSS, from rates of morbidity and mortality are high. DF is characterized by fever of 3-5 days,' duration. headache, muscle and joint pain and a rash which is self limited and from which patients usually recover completely. There is no specific treatment for DF, and most forms of therapy are supportive in nature. DHF-DSS is characterized by the same signs and symptoms as classic DR but it is followed by increased vascular permeability and hemorrhage, which may lead to vascular collapse and death. Careful clinical management by experienced medical professionals is important in saving the lives of DHF patients. Diagnosis of dengue virus infection on the basis of clinical syndromes is not reliable, and the diagnosis should be confirmed by laboratory studies, because more than half of infected individuals either are asymptomatic or have a un differentiated fever 8:22. Therefore, there is a great demand for the rapid detection and differentiation of dengue virus infection in the acute phase of illness in order to provide timely clinical treatment.

\section{MATERIALS AND METHODS METHODOLOGY}

The present study was conducted at Mamata General Hospital, Khammam. An alarmingly increasing epidemic of dengue was noticed in this part of state, with more number of admissions of dengue cases. Hence, the following study was conducted to find out the early clinical manifestations and laboratory parameters in Dengue fever.

100 patients of age of more than 13 years presenting with signs and symptoms suggestive of Dengue fever as per who criteria were included in the study between June 2014 - July 2015. Written consent was taken from patients before enrolling in study. Complete history and clinical examination was done.The results were tabulated and correlated.

All suspected cases are subjected to IgG, IgM, antibody, and NS I antigen testing.

And confirmed cases are subjected to routine hematological and other clinical investigations

\section{DENGUE FEVER (DF) (W.H.0)}

\section{Clinical Case Definition:}

An acute febrile illness of 2-7 days duration with 2 or more of the following:

- Headache

- Retro-orbital pain

- Myalgia

- Arthralgia

- Rash

- Hemorrhagic manifestations

- Leucopoenia

\section{LABORATORY CRITERIA FOR DIAGNOSIS}

Any one or more of the following:

- Isolation of dengue virus from serum, plasma, leukocytes, or autopsy samples 
- Demonstration of a fourfold or greater change in reciprocal IgG or IgM Antibody titers

- Demonstration of Dengue virus antigen

\section{METHODS:}

- IgG antibody testing

- $\operatorname{IgM}$ antibody testing

- NS I antigen testing

\section{ROUTINE BLOOD INVESTIGATIONS:}

- Mean hemoglobin

- Mean hematocrit

- Mean total leucocyte count

- Mean neutrophil count

- Mean lymphocyte count

- Mean platelet count

\section{INCLUSION CRITERIA:}

- All patients above 13 years with fever

- With rash, bleeding manifestations, sore throat, abdominal pain, bradycardia, headache

- All cases attending to 0.P, 1.P with fever to Mamatha General Hospital, Khammam, Telangana.

\section{EXCLUSION CRITERIA:}

- Diagnosed cases of thrombocytopenic purpura on treatment

- Patients with thrombocytopenia already diagnosed to have hematological disorder / malignancy, on treatment with chemotherapy and other immunosuppressants

- Diagnosed cases of platelet disorders and dysfunction

- Patients on treatment with antiplatelet drugs and other drugs causing thrombocytopenia

- Patients with cirrhosis and chronic liver disease

- Concomitant cases of other bacterial and viral infections.

Study duration: 1 year period
Study design: Prospective study

\section{RESULTS}

In this study out of 100 patients $56 \%$ were presented with PLC of $<100,000$, in them 28 $(50 \%)$ were male, $28(50 \%)$ were female, 2 patients $(35 \%)$ were presented with the PLC of 20000, 12 patients $(21.4 \%)$ were presented with the PLC of 21-40000, in them 7 were male, 5 were female.18 patients $(32.1 \%)$ were presented with the PLC of $41-60000$ in them 8 were male, 10 were female, and 10 patients (17.8\%) were presented with PLC of $61-80000$, in them 5 were male, 5 were female, 14 patients $(25 \%)$ were with the PLC between 81-100000, in them 6 were male 8 were female 4 patients developed complications like ARDS, Respiratory failure, AKI, MODS. In this study $5 \%$ mortality was observed out of them 4 were male, 1 female patient. Out of 5 patients 4 presented with plc<100,000.In this study 55 patients were positive for NS 1 antigen, 24 patients were positive for $\operatorname{IgG}, \operatorname{IgM}$ antibody and NS1 antigen, 21 patients were positive for $\mathrm{IgG}$ and IgM.

\section{DISCUSSION}

Dengue infection is systemic and dynamic disease. In the recent few years varied clinical manifestations of dengue fever seen in different epidemics from different parts of the world. Early recognition and meticulous management are very important to save precious Iives from this killer disease,

\section{AGE:}

In this study more number of dengue cases was reported between the age group of 21-30years

- Goh kt 74 et al, have reported dengue fever occurrence and morbidity in adults.

SEX: Female to male ratio was 1:1 both genders equally affected.

\section{CLINICAL PROFILE:}

Fever was the most common presenting symptom, seen in 98\%patients similar studies in around India have also substantiated fever as being the 
most common presenting symptom. Fever followed by myalgias $61 \%$,vomiting $41 \%, 15 \%$ pain abdomen, $6 \%$ head ache and bleeding manifestations, $5 \%$ with jaundice, $4 \%$ with loose stools.

Clinical presentation in this study similar to that which were seen in other studies.

Anuradha et al75, found fever as most common presentation (100\%), followed by vomiting in $8 \%$, bleeding manifestations in $52.6 \%$.

Narayana et aim, study reported fever in $98.3 \%$, vomiting in $80 \%$, abdominal pain in $22 \%$, bleeding manifestation in $66 \%$.

It is imperative to keep in mind that other infections that cause fever and gastro intestinal symptoms may often lead to a delay in diagnosis of Dengue. This conclusion was also made from a study done in tertiary care centre in Pakisthan.

Most common bleeding manifestations in this study were petechiae, bleeding per vaginum, melena hematuria

Thrombocytopenia seen in 56\%patients, which was similar to study by Ahmed et cal78, that thrombocytopenia was seen in $65 \%$ patients. Platelet count between 81,000-100,000 seen in 14 patients, PLC between $61-80,000$ seen in 10 patients. patients presented with the PLC between In between 41-60000 seen in 18 patients, 12 I40000 , in 2 patients PLC was 20,000

In Malavige et al", reported plc between 50 and 100,000 was $24.2 \%, 20-50000$ was $46 \%$ d $<20000$ in $30 \%$ patients. In this study thrombocytopenia is associated with to bleeding manifestations and DHF, DSS in $7 \%$ cases.

In this study leucopenia was observed in $39 \%$ cases, a study by Arif et .alg' was observed in $43 \%$, Ratageri et al study showed $26 \%$, Itoda et al81, study showed d leucopenia in $71 \%$ cases.

Laboratory findings were compared between DF, DSS, and DHF. In total 100 cases 6 cases were DSS, 3 cases were DHF. Mean $\mathrm{HB} \%$ was 11.9 \pm 2.6 in DF, $6.7+4.2$ in DHF, $9.3 \pm 2.8$ in DSS. Mean HCT was $33.09 \pm 7.5$ in DF, $21+10.8$ in DHF, 29.6 \pm 4.17 in DSS. Mean neutrophil count was $69.4 \pm 12.5$ in DF, $77 \pm 13.9$ in DI-IF, $74 \pm 11.6$ in DSS. Mean PLC at admission was $81321 \pm 8729$ in DF, $136666 \pm 75055$ in DI-IF, 68840 \pm 67407 in DSS. Mean PLC at discharge $103431 \pm 54175$ in DF, $40333 \pm 34383$ in DHF, 58200+11150 in DSS. Mean TLC was $5550 \pm 3768$ in DF, $17233 \pm 1266$ in $131-1 \mathrm{~F}, \quad 7750 \pm 1436$ in DSS. Mortality was observed in 5\% patients in them 4 were male, 1 was female. Other studies showed morbidity highest in older adults. In 100 patients 55\% were positive for NS I antigen, 24\% were positive for IgG, IgM antibody and ns1 antigen, 2 I \% patients were positive for both $\mathrm{IgG}$ and $1 \mathrm{gM}$.

\section{CONCLUSION}

The present study had an objective of studying early clinical manifestations, hematological profile associated with the disease for appropriate management. In our study $21-30$ years age group patients were more affected. Fever was most common symptom, followed by myalgias and vomiting. Platelets were decreased in $56 \%$. Leucopenia was observed in $36 \%$.Importance should be given to symptoms like fever, myalgias, retro orbital pain, abdominal pain, if these are associated,with low platelet count ,especially during Dengue epidemics Dengue should be considered differential diagnosis who presented with above symptoms.

Blood pressure, Pulse, Heamatocrit should be monitored along with total leukocyte count as leucopenia noted in febrile period, then leukocytosis in dengue with secondary infection.

Warning signs and bleeding tendencies should be closely watched for disease progression to DSS or DHF.

The treatment of Dengue is mainly supportive, but early institution and meticulous monitoring are the corner stone for positive outcome along with vector preventive measures

\section{SUMMARY}

100 serologically confirmed cases were studied from June 2014-2015.

Most common age group affected was 21-30 years

Female to Male ratio was 1:1 
Fever was the most predominant symptom $98 \%$, followed by myalgia $61 \%$ and vomiting $41 \%$

Mean duration of fever was 6.1 day

$56 \%$ patients presented with PLC $<100,000$, in them 2 patients developed DSS, 1 patient developed DHF. Another 4 patients developed bleeding manifestations.

Out of hundred 39 patients developed leucopenia.

$55 \%$ positive for NS1 antigen, $24 \%$ were positive for $\mathrm{IgG}, \mathrm{IgM}$ antibodies.

$5 \%$ mortality observed in them 4 were male and 1 female.

Complications associated with Dengue were AKI, MODS, ARDS and Respiratory Failure.

\section{BIBILOGRAPHY}

1. Gibbons ,R.V, and D.W Vaughan .2002. Dengue; An escalating problem.BMJ 324;1563-1566

2. World Health Organisation .1997. Dengue heamorrhagic fever. Diagnosis ,treatment, prevention and control, $2^{\text {nd }}$ edition W.H.O

3. Gubler .1998.Dengueand Dengue Heamorrhagic fever Clin.

Microbiol.Rev.11;480-496

4. Chambers, T.J.C.S.Hahn, R.Galler, and C.M.Rice.Flavi virus replication expression and genome organisationannu .Rev.Microobial44649-688

5. Deubel,V,R.M. Kidney and D.W Trent 1998. Virology 165;234-244

6. Lyssen. P,E.D Clereqand J.Neyts .2000.Clin Microbiol Rev.13;67-82

7. Rice ,C.M,E.M.Lenches 1985 . Science 229;726-733

8. Burked,d.S.A..Nisalak, D.E.Jhonson ,1988 A Prospective study of Dengue infraction in bankok Trop .Med.Hyg.38;172-180

9. GuzmaM.G.G.Kouri1990.Dengue heamorrahagic fever in cuba 1981Trop .Med.Hyg.421;179- 184

10. Halstead ,S.B,.H.Shotwell1973 Inf.Dis. $128 ; 15-22$

11. Halstead,S.B.1988.pathogensis of Dengue .Sicence239;476-481
12. Gubler,D.J.,D.Reed

I.Rose

and

J.C.J.Hitchcock.1978

Epidemiological,Virological,

Clinical observations on Dengue.Am.J. Trop.Med.Hyg. 27;581-589

13. Rosen,11977 Pathogenesis of Dengue fever.Trop.Med.Hyg.26;337-343

14. Green.S.D.,W.Vaughn et al.,1999 Early immune activation in dengue related to plasma leakage and severity.J.Infect.Dis.179;755-762

15. Kurane,L,A, I.Rothman.et al 1994.Immunopathologic mechanism of dengue heamorrhagic fever and dengue shock syndrome .Arch.Virol.Suppl.9;5964

16. Vaughn.d. w., et al Dengue Viremia titre , antibody response pattern and virus serotype correlate with disease severity .J.Infect.DIS.181;2-9

17. lei.H. Y., TM. Yeh., et al . immunopathogenesis of Dengue fever .J.Biomed.Science2001.8;377-388

18. Lin,C.F.,H.Y.Lei.et al . generation of IgM antiplatelet antibody in dengue patient .J.Med .Virol.63:143:-496

19. Gubler.D.J et al .1998 Dengue and Dengue heamorrhagic fever.Clin.Microbiol.Rev. $11 ; 480-496$

20. Guzman.M.G and Kouri et al., Dengue : an update .Lancet Infect.Dis.2:33-42

21. Nimmannitya,s.1987.Clinical spectrum and management of Dengue haemorrhagic fever J..Trop.Med.Public Health 18:392397

22. Endy T.P. et al. Epidemilogy of inapparent and symptomatic acute Dengue virus infection .Am.Jj.Epidemiol. 156:40-51

23. Perez JGR, Clark GG, Gubler DJ, Reiter P,,SandersEJ, Vorndam AV.Dengue and Dengue haemorrhagic fever Lancet 1998;352:971-977

24. World health organisation , Dengue haemorrhagic fever :Diagnosis treatment and Control Geneva:WHO 1986 
25. Carey DE. Chickngunya and Dengue :A case of mistaken identity ? J Hist Med 1971;26:243-62

26. Ehernkranz NJ, Ventura AK, Caudrado RR. Pond WL, Porter pandemic Dengue in caribean contries and southern united states ; past, present and potential problems. NEJM 1971;285:1460-69.

27. Halstead SB. Dengue hemorrhagic fever : a public health problem and a field for research. Bull WHO 1980 ;58:1-21

28. Cohen SN , Halstead SB. Shock associated with Dengue infection. J peditar 1966;68:448-56

29. Communicable disease surveillance and response, WHO 2002, http;//www.who.int/entity/csr/disease/Dengue

30. Chandrakantha, Rashmi kumar ,Garima, Jyosthma Agarwal, Amitha jain, Rachana nagar. Changing clinical manifestation of Dengue in north india. Dengue bulletin 2008;32:118-126

31. Janak Kishore , Jagadeep Singh , T.N Dhole and A Ayyagari. Clinical and serological study of first large epidemic of Dengue in and around Luknow, India , Dengue bulletin, 2006;30;72-80

32. Carey DE, Myers RM , Ruben R,Rodrigues FM. Studies on Dengue in Vellore, south india. Am J Trop Med Hyg. 1996;15;580-7

33. Sabin AB. Research on Dengue during worls war 2. Am J Trop Med Hyg . 1952;1:30-49

34. Hammon WMcD. Dengue hemorrhagic fever, Do we know its cause? Trop Med Hyg 1973;22:82-91

35. Hammon WMcD. Runick A, Sather GE . Virus associated with epidemic hemorrhagic fever of the Philippines and Thailand . Sciences 1960;131:1102-3

36. World health organisation WHO. Dengue hemorrhagic fever . diagnosis prevention and control, $2^{\text {nd }}$. Geneva :WHO 1997AA
37. Harrigton LC, Edman JD, Scott TW. Why do female Aedes feed preferentially and frequently on human blood ? J Med Entemol 2001;38:411-422

38. Halstead SB . Selective primary health care : Strategies for control of disease in the developing world .XI. Dengue Rev infect Dis 1984;6:251-64

39. McBride WJ, Bielefeldt-Ohman H.Dengue viral infections: pathogenesis and epidmology.Microbes Infect 2000;2: 1041-1050

40. Cheong LL. The vectors of Dengue and Dengue hemorrhagic fever in Malasyia . In: Rundick A , Lin TW, Editors . Dengue fever studies in malasyia bulletin 23, Kaulalampur, malasyia: institute of Medical Research . 1986

41. World health organisation . Dengue and Dengue hemorrhagic fever .Fact sheet no. 117 www.who.int/inf-fs/en/fact117.html.

42. Kurane, Takasaki $\mathrm{T}$, Yamada K .Trends in Flavi virus Infection in Japan.Emerg Ifect Dis 2000;6:569-571.

43. From the centes for diseas control and prevention .Imported Dengue-united states , 1997 and 1998. JAMA 200;283:19531954.

44. Gubler DJ. Aedea aegypti and Aedes aegypti - borne disease control in the 1990s:top down or bottom up ?Charles franklin Craig lectures . Am J Trop Med Hyg. 1989;40:571-578.

45. Burke DS, Nisalak A, Jhoonson DE.Scott RM. A Prospective of dengue infection in Bankok . Am J Trop Med Hyg 1988;38:172-180

46. Krishnamurthi C, Kalayanarooj S, Cutting MA , Peat RA ,Roathwell SW, Reid TJ et al. Mechanism of hemorrhage in dengue without circulatory collapse. Am J Trop Med Hyg 2001;65:840-847.

47. Wu SJ , Grouard-Vogel G, Sun W, Mascola JR, Brachtel E, Putuvatanaa R, et al. Human skin langerhanss cells are 
target of dengue virus infection . Nat Med 2000;6:816-820.

48. Halstead SB. Antibody , Macrophages, Dengue virus infection, shock, and hemorrhage ; a pathogenic cascade .Rev infect. Dis 1989;11:s830-9.

49. Rosen L. COmements on epidemiology, pathogensis, and control of dengue . Med Trop 1999;59:495-498.

50. Solomon T, Dung NM, Vaughn DW, et al . Neurological manifestations of Dengue infection . Lancet 2000;355:1053-1059.

51. Cam BV, Fonosmark L, Hue NB, et al. Prospective case control study of enchepalopathy in Dengue hemorrhagic fever in children. Am J Trop Med Hyg 2001;65:848-851.

52. Vaughn DW, Green S, kalayanarooj S, et al. Dengue viremia titer, antibody response pattern, and virus serotype correlate with disease severity. J Infect .Dis 2000;181:2-9.

53. Sullivan NJ. Antibody mediated enhasment of viral disease. Curr top microbial Immunol 2001;260

54. K urane I, Takasaki T. Dengue fever and Dengue hemorrhagic fever : challenges of controlling an enemy still at large. Rev Med Virol 2001;11;301-311.

55. Sumarmo . The role of steroids in Dengue shock syndrome . South East Asian J Trop Med Public Health 1987;18:383-389.

56. Nimmantiya S. Dengue Hemorrhagic fever with unusal clinical presentations. South East Asian J Trop Med Public Health 1987 ;18:398-406

57. Halstead SB . The pathogenesis of Dengue ; The Alexander D.Langmuir Lecture. Am J Trop Med Hyg 1981;114:632-48

58. Sangkawahbia N, Rojanasuphot S , Ahandrik $S$ et al.Risk factor in Dengue shock syndrome . A prospective epidemicological study in Rayong, Thailand Am J Epidemol 1984;120:653-69
59. Gubier DJ. Dengue In: Monath TP ed.The arbovirus :Epidemology and ecology . Bocca Raton , FLA:CRC Press , 1988:22360.

60. Sumarmo WH, Jaha E, Gubler DJ , et al . Clinical observations in vipologically confirmed fetal dengue in Djakartha , Indonasia .Bull WHO 1983;61:693-701.

61. Sharp TW , WallaceMR, Hayes CG, Sanchez JL, DeFraites RF, Arthur RR, et al. Dengue fever in US troops during operation Restore Hope , Somalia, 19921993 Am J Trop Med Hyg 1995;53:89-94.

62. Waterman SH, Gubler DJ. Dengue fever. Clin Dermatol 1989;7:117-122.

63. Dietz VJ, Gubler DJ, Rigau-perez JG, Pinheiro P, Schatzmayr HG, Baily R et al.Epidemic Dengue 1 in Brazil, 1986: evalution of a clinically based Dengue surveillance system. Am J Epidemiol 1990;131:4.

64. World health organisation Technical Guides for diagnosis treatment , surveillance, prevention and control of Dengue hemorrhagic fever.Geneva;WHO , 1975.

65. George R, Liann CK, chua CT , Lam SK, Pang T, Geethan R, Foo LS. Unusal clinical manifestations of Dengue virus infection . Southeast Asian J Trop Med Public Health. 1998;19:585-590.

66. Lum LCS, Lam SK, Choy YS, George R , Harun F. Dengue Enchepalitis: a true entity? Am J Trop Med Hyg. 1996;54:256259.

67. Lum LCS, Thong MK, Cheah YK and Lam SK Dengue -associated adult respiratory distress syndrome .Ann Trop Paediatrics . 1995;15:335-339.

68. Lum LCS, Lam SK, George R and Devi S. Fluminant hepatitis in Dengue infection. Southeast Asian J Trop Med Public Health 1993;24;467-471

69. Chye JK, Lim CT, Ng KB, Lim JMH, George R, Lam SK. Vertical transmission 
of Dengue Clin Inf Dis. 1997;25:13741377.

70. Liu CC, Haung KJ , Lin YS, Yeh TM, Liu HS, Lei HY. Transient CD4/CD8 ratio inversion and abeerant immune activation during Dengue virus infrction. J Med Virol. 2002 Oct;68(2):241-52.

71. Rueda E, Mendez A ,Gonzalez G. Hemophagocytic syndrome associated with Dengue hemorrhagic fever . Biomedica (Bogota). 2002;22:160-6.

72. Nhan NT, Cao XT, Kneen R, Wills B, Nguyen VM, Nguyen TQ et al. Acute management of Dengue shock syndrome ; a randomized double- blind comparison of 4 intravenous fluid regimens in the first hour. Clin Infect Dis 2001;32:204-213

73. Goh KT, Ler, Teck Siang:Epidemilogical characteristics of the 2005 and 2007 Dengue epidemics in Singapore. West pacific survie J;Oct 2011;2:4-24.

74. Anuradha S, Singh NP, Rizvi SN, Agarwal SK, Gur R, Mathur MD. The 1996 outbreak of dengue hemorrhagic fever in delhi, India;Southeast Asian J Trop Med Public Health. 1998;29:503-6.

75. Narayanan M, Aravind MA, Thilothammal N, Prema R, Sargunam Rex CS et al. Dengue fever Epidemic in Chennai - A Study of clinical profile and Outcome . Indian pediatr 2002;39:1027-1033.

76. Mahboob M, Iqbal Z, Javed R, Taj A, Mumir A, Akthar SM. Clinical characteristics of the patient with dengue fever ; Report of 48 patients in $2010 \mathrm{~J}$ Ayub Med col Abbottabad 2010;22(4).

77. Ahmed , F.U., B.C. Mahmood , J.D. Sharma, S.M. Hoque et al. Dengue and Dengue hemorrhagic fever in Chittagong, Bangladesh, Dengue Bull.25:33-39

78. Malavig, G.N., P.K Ranatunga, S.D jayaratne et al. 2007. Dengue viral infection as a cause of encephalopathy . Indian .J.Med. Microbiol.25(2):143-5
79. Arif, Y.Yahya, Ahmed and Akram, D.S 2008. Dengue fever out break in Karachi2006- Astudy of profile and outcome of children under 15 years of age JPMA.58(1):4-8.

80. Itoda I, Masuda G, Suganuma A, Imamura A, Ajisawa A, et al. Clinical features of 62 imported cases of Dengue fever in Japan . Am J Trop Med Hyg.2006 Sep;75(3);4704. 